\title{
Polysaccharides isolated from Morinda officinalis How roots inhibits cyclophosphamide-induced leukopenia in mice
}

\author{
Yaxin Zhao ${ }^{1}$, Meng Wang ${ }^{2}$, Yang $\mathrm{Li}^{3 \star}$ and Wanting Dong ${ }^{4}$ \\ ${ }^{1}$ Department of Pharmacy, ${ }^{2}$ Medical Department, ${ }^{3}$ Chinese Medicine Department, Jining Traditional Chinese and Western \\ Medicine Hospital, Jining 272000, Shandong, PR China;, ${ }^{4}$ Ministry of Education, Jining No. 1 People's Hospital, Jining 272000, \\ Shandong, PR China
}

*For correspondence: Email: tcmliyang@126.com; Tel: +86-0537-3168581

\begin{abstract}
Purpose: To investigate the optimum parameters for extracting polysaccharides from Morinda officinalis How (MOP), and explore their inhibitory effects on leukopenia in mice.

Methods: Orthogonal design was performed to investigate the optimum parameters for extracting MOP. A leukopenia mouse model was established by injection of cyclophosphamide (CTX) for three days. Thereafter, MOP (100, 200 and $400 \mathrm{mg} / \mathrm{kg})$ was administered orally for 10 days. Furthermore, blood cells (leukocytes, neutrophil, lymphocyte and mononuclear cell) were analyzed, while serum IL-3 and IL6 were determined by ELISA. The thymus and spleen of the mice were separated and weighed to determine viscera indices.

Results: Orthogonal design showed that the influence order of the four factors was extraction times (C) $>$ ratio of water to raw material $(R W M, D)>$ extraction time $(B)>$ extraction temperature $(A)$. The optimum extraction parameters for MOP were: extraction temperature $\left(80{ }^{\circ} \mathrm{C}\right)$, extraction duration $(2 \mathrm{~h})$, no. of extractions (3), and ratio of water to raw material $(30 \mathrm{~mL} / \mathrm{g})$. Furthermore, the results indicate that MOP $(100,200$ and $400 \mathrm{mg} / \mathrm{kg})$ elevated the levels of leukocyte $(p<0.01)$, neutrophil $(p<0.01)$, lymphocyte $(p<0.01)$ and mononuclear cell $(p<0.01)$ in leukopenia mice. Besides, MOP (100, 200 and $400 \mathrm{mg} / \mathrm{kg})$ also increased thymus $(p<0.01)$ and spleen $(p<0.05)$ indices and serum levels of IL-3 $(p<$ $0.05)$ and IL-6 $(p<0.01)$.

Conclusion: Orthogonal design is a good strategy for optimizing extraction parameters of MOP. Furthermore, MOP stimulated synthesis of leukocytes in CTX-induced leukopenia in mice. Thus, MOP is a potential adjunct for the treatment of tumors/cancers.
\end{abstract}

Keywords: Morinda officinalis, Polyscacharide, Orthogonal design, Leukopenia, Thymus index, Spleen index

Tropical Journal of Pharmaceutical Research is indexed by Science Citation Index (SciSearch), Scopus, International Pharmaceutical Abstract, Chemical Abstracts, Embase, Index Copernicus, EBSCO, African Index Medicus, JournalSeek, Journal Citation Reports/Science Edition, Directory of Open Access Journals (DOAJ), African Journal Online, Bioline International, Open-J-Gate and Pharmacy Abstracts

\section{INTRODUCTION}

In recent years, studies have demonstrated that malignant cancers have become one of the most common incurable diseases worldwide [1]. For the treatment of cancers, besides surgery, longterm chemotherapy is another commonly used effective method [2]. However, chemotherapy could result in myelosuppression, leading to many serious side-effects, especially leukopenia [3]. Leukopenia could result in extremely low leukocyte levels in the body, causing hypoimmunity. In this situation, severe inflammatory cascades reactions could be induced, leading to sepsis and even death [4]. 
Thus, it is important to prevent leukopenia in the process of chemotherapy for treating cancers.

Currently, existing drugs for elevating levels of leukocytes, such as vitamin B6, leucogen and granulocyte colony-stimulating factors (GCF), cannot enhance body immunity, but only increase the cell number of leukocytes [5]. Increasing investigations have demonstrated that traditional herbal medicines are tremendous resources for finding novel drugs for treating various diseases, especially some incurable diseases [6,7]. A previous report indicated that Morinda officinalis How, a folk traditional herbal medicine in China, possesses notable immunity enhancing effects and could be used for treating leukopenia induced by chemotherapeutic agent [8-10]. However, information on the details of the active substances in $M$. officinalis is lacking. Therefore, in this study, the isolation of the polysaccharide of $M$. officinalis (MOP) was optimized using orthogonal design, and the inhibition of MOP on leukopenia induced by cyclophosphamide (CTX) in mice was also investigated.

\section{EXPERIMENTAL}

\section{Plant material}

The roots of Morinda officinalis How were purchased from Tongrentang Chinese Medicine Co. Ltd. (Beijing, China) and authenticated by a taxonomist in the Chinese Medicine Department of Jining Traditional Chinese and Western Medicine Hospital (Jining, China). A voucher specimen (no. BJT2015-7-4H) was kept in the herbarium of the department for future reference.

\section{Animals}

BALB/cmice (20 $\pm 2 \mathrm{~g}$ ) were purchased from the Experimental Animal Center of the Academy of Military Medical Sciences (Beijing, China). All animal protocols in this study were in accordance with the guidelines of National Institute of Health Guide for the Care and Use of Laboratory Animals [11], and were approved by the ethics committee of Traditional Chinese and Western Medicine Hospital (approval no. AER-2015-6-01).

\section{Chemicals and reagents}

Cyclophosphamide injection (CTX) was purchased from Jiangsu HengRui Medicine Co. Ltd. (Lianyungang, China). Pentobarbital sodium was purchased from Sigma-Aldrich Co. (Shanghai, China). Interleukin (IL)-3 and 9 ELISA kits were purchased from BOSTER Co. (Wuhan, China). D-glucose standard agent was purchased from the National Institute for the Control of Pharmaceutical and Biological Products (Beijing, China). All other chemicals and reagents used in this study were all of analytical grade (AR).

\section{Isolation of polysaccharides from roots of $M$. officinalis}

The dried roots of $M$. officinalis were powdered and then extracted with $95 \%$ ethanol for $8 \mathrm{~h}$ to remove monosaccharides, oligosaccharides and other small molecule agents. Then, the residues after filtration were extracted with distilled water by hot dipping. The extracts were cooled at room temperature, and subsequently concentrated. Then, ethanol was slowly added to a final concentration of $80 \%$. The precipitates were collected after leaving overnight at $4{ }^{\circ} \mathrm{C}$ in a refrigerator. Then the precipitates were washed three times with absolute ethanol and acetone, and subsequently dried by freeze drying as to obtain MOP.

\section{Determination of polysaccharide yield}

The polysaccharide contents were determined according to the previous described phenolsulfuric method using D-glucose as standard reference [11-12]. The calibration curve between absorbance (A) and polysaccharide contents (C) in this study is $A=0.0075 C+0.04(r=0.9986)$. Polysaccharide yield (\%) was calculated as in Eq 1.

Yield $(\%)=\left(W_{1} / W_{0}\right) 100$

where $W_{1}$ is weight $(\mathrm{g})$ of polysaccharides, and $\mathrm{W}_{0}$ is the weight $(\mathrm{g})$ of dried herbal material.

\section{Orthogonal design and statistical analysis}

Based on previous investigations regarding polysaccharide isolation, four major influence factors were investigated namely extraction temperature $(A)$, extraction time $(B)$, extraction times (C), and ratio of water to raw material (RWM, D). To optimize the extraction of polysaccharide of $M$. officinalis (MOP), the orthogonal design was performed with L9 $\left(3^{4}\right)$ experiment and the four factors were subjected into three levels (Table 1). All the tests were repeated three times, and the range analysis and variance analysis (ANOVA) were conducted to analyze the orthogonal design results. 
Table 1: Influence factors and levels values in the orthogonal design

\begin{tabular}{lcccc}
\hline \multirow{2}{*}{$\mathbf{S} / \mathbf{N}$} & $\boldsymbol{4}$ Factor \\
\cline { 2 - 5 } & $\boldsymbol{A}:$ Temperature $\left({ }^{\circ} \mathrm{C}\right)$ & $\boldsymbol{B}:$ Time $(h)$ & $\boldsymbol{C}:$ Times $(n)$ & $\boldsymbol{D}: R W M(\mathrm{~mL} / \mathrm{g})$ \\
\hline 1 & 80 & 1 & 1 & 10 \\
2 & 90 & 2 & 2 & 20 \\
3 & 100 & 3 & 3 & 30 \\
\hline
\end{tabular}

$R W M=$ ratio of water to raw material

\section{Determination of effect of MOP on leukopenia mice induced by CTX}

Fifty BALB/c mice were randomly divided into five groups $(n=10)$ : normal group, control group, three MOP treated groups $(100,200$ and 400 $\mathrm{mg} / \mathrm{kg}$ ). Mice in control and MOP groups were intraperitoneally injected with CTX (80 mg/kg, ip) for three days to induce leukopenia. Then, mice in the normal, control and MOP treated groups were administrated orally with normal saline (20 $\mathrm{mL} / \mathrm{kg})$, normal saline $(20 \mathrm{~mL} / \mathrm{kg})$ and MOP $(100$, 200 and $400 \mathrm{mg} / \mathrm{kg}$ ) for 10 days, respectively. Blood samples were collected using an abdominal aortic blood sampling protocol under anesthesia with pentobarbital sodium $(45 \mathrm{mg} / \mathrm{kg}$, ip), and then mice were subsequently sacrificed by decapitation. The blood cells (leukocytes, neutrophil, lymphocyte and mononuclear cell) were analyzed using a full automatic blood analyzer (SYSMEX XE2100, Kobe, Japan). In addition, the serum IL-3 and IL-6 were determined using commercial ELISA kits according to the manufactures' instructions. Finally, thymus and spleen were separated and weighed to determine viscera index $[4,14]$ using Eq 2.

Viscera index $=\left(M_{1} / M_{0}\right) 10$

where $M_{1}$ is the weight (mg) of thymus or spleen, and $\mathrm{M}_{0}$ is the weight $(\mathrm{g})$ of the mice.

\section{Statistical analysis}

One-way ANOVA following by Dunnett multiple comparisons tests was used to analyze the differences between different groups with SPSS software (SPSS for Windows 15.0, SPSS Inc., USA). Data are expressed as mean \pm SD, and differences were considered significant at $p \leq$ 0.05 .

\section{RESULTS}

\section{Optimized extraction by orthogonal design}

As can be seen from the Table 2, the range analysis results of orthogonal design showed that among the four factors, extraction times (C) and RWM (D) are the dominating influence factors for the MOP extraction rate with an $R$ value of 1.100 and 0.803 respectively, followed by the extraction time $(B, R=0.477)$ and extraction temperature (A, $R=0.143$ ). From the range analysis results showed in Table 2, the influence order of the four factors was $C>D>B>A$, and the optimum extraction was $C_{3} D_{3} B_{3} A_{1}$. Based on the range analysis results, ANOVA was also determined, and the results showed that the extraction times and RWM were significant $(F<0.05)$ (Table 3 ). However, no obvious significance was observed in the extraction temperature $(\mathbf{A})$ and extraction time (B) $(F>0.05)$.

Collectively, combined with realistic conditions, the optimum extraction was obtained: extraction temperature of $80^{\circ} \mathrm{C}$, extraction time of $2 \mathrm{~h}$, extraction times of 3 , and ratio of water to raw material weight of $30 \mathrm{~mL} / \mathrm{g}$.

Table 2: Results of range analysis of orthogonal design

\begin{tabular}{lccccc}
\hline No. & A & B & C & D & Yield (\%) \\
\hline 1 & 1 & 1 & 1 & 1 & 3.54 \\
2 & 1 & 2 & 2 & 2 & 5.27 \\
$\mathbf{3}$ & $\mathbf{1}$ & $\mathbf{3}$ & $\mathbf{3}$ & $\mathbf{3}$ & $\mathbf{5 . 8 6}$ \\
4 & 2 & 1 & 2 & 3 & 5.15 \\
5 & 2 & 2 & 3 & 1 & 4.67 \\
6 & 2 & 3 & 1 & 2 & 5.21 \\
7 & 3 & 1 & 3 & 2 & 4.81 \\
8 & 3 & 2 & 1 & 3 & 4.62 \\
9 & 3 & 3 & 2 & 1 & \\
\hline k1 & 4.890 & $\mathbf{4 . 6 3 3}$ & $\mathbf{4 . 3 4 0}$ & $\mathbf{4 . 4 7 0}$ & \\
k2 & $\mathbf{5 . 0 2 3}$ & $\mathbf{5 . 1 1 0}$ & 5.013 & 5.050 & \\
k3 & $\mathbf{4 . 8 8 0}$ & 5.050 & $\mathbf{5 . 4 4 0}$ & $\mathbf{5 . 2 7 3}$ & \\
$R$ & 0.143 & 0.477 & 1.100 & 0.803 & \\
\hline
\end{tabular}


Table 3: Results of variance analysis (ANOVA) of orthogonal design

\begin{tabular}{lccccc}
\hline Factor & Sum of square & Freedom & F-ratio & $\mathbf{F}_{\mathbf{0 . 0 5}}$ & Significance \\
\hline Temperature $\left({ }^{\circ} \mathrm{C}\right)$ (Error group) & 0.038 & 2 & 1.000 & 19.000 & \\
Time $(\mathrm{h})$ & 0.404 & 2 & 10.632 & 19.000 & \\
Times $(\mathrm{n})$ & 1.845 & 2 & 48.553 & 19.000 & $F<0.05$ \\
RWM $(\mathrm{mL} / \mathrm{g})$ & 1.032 & 2 & 27.158 & 19.000 & $F<0.05$ \\
\hline
\end{tabular}

$R W M=$ ratio of water to raw material

Table 4: Blood count in CTX-treated mice $\left(10^{9} / \mathrm{L}\right)$

\begin{tabular}{|c|c|c|c|c|}
\hline Treatment & Leukocytes & Neutrophil & Lymphocyte & Mononuclear cell \\
\hline Normal & $10.13 \pm 1.85^{\star *}$ & $1.22 \pm 0.36^{\star *}$ & $9.13 \pm 1.46^{* *}$ & $0.52 \pm 0.11^{\star \star}$ \\
\hline Control & $1.13 \pm 0.35$ & $0.37 \pm 0.14$ & $0.67 \pm 0.19$ & $0.09 \pm 0.02$ \\
\hline $100 \mathrm{mg} / \mathrm{kg}$ & $5.74 \pm 0.85^{\star *}$ & $0.62 \pm 0.22^{* *}$ & $4.88 \pm 0.52^{* *}$ & $0.28 \pm 0.05^{\star *}$ \\
\hline $200 \mathrm{mg} / \mathrm{kg}$ & $7.61 \pm 1.23^{\star *}$ & $0.83 \pm 0.35^{\star *}$ & $6.51 \pm 0.85^{\star *}$ & $0.33 \pm 0.08^{* *}$ \\
\hline $400 \mathrm{mg} / \mathrm{kg}$ & $9.58 \pm 1.67^{\star \star}$ & $0.93 \pm 0.41^{* *}$ & $8.26 \pm 1.03^{\star *}$ & $0.44 \pm 0.12^{\star *}$ \\
\hline
\end{tabular}

MOP elevated levels of leukocyte, neutrophil, lymphocyte and mononuclear cell

From the results shown in Table 4, after the CTX injection $(80 \mathrm{mg} / \mathrm{kg})$, all of the four testing cells were sharply decreased $(p<0.01)$, suggesting that leukopenia was successfully established by CTX injection. Interestingly, the results also demonstrated that the MOP $(100,200$ and 400 $\mathrm{mg} / \mathrm{kg}$ ) elevated the decreased levels of leukocyte $(p<0.01)$, neutrophil $(p<0.01)$, lymphocyte $(p<0.01)$ and mononuclear cell $(p<$ 0.01) compared to control mice in a dosedependent manner.

\section{MOP increased thymus and spleen indices}

As shown in Figure 1, both the thymus and spleen indices of control mice were decreased compared with normal mice $(p<0.01)$. After treatment with MOP (100, 200 and $400 \mathrm{mg} / \mathrm{kg}$ ) for 10 days, the thymus indices were significantly increased compared to the control group $(p<$ 0.01), in a dose-dependent manner. In addition, MOP at $200(p<0.05)$ and $400 \mathrm{mg} / \mathrm{kg}(p<0.01)$ also increased the spleen indices compared to the control group.

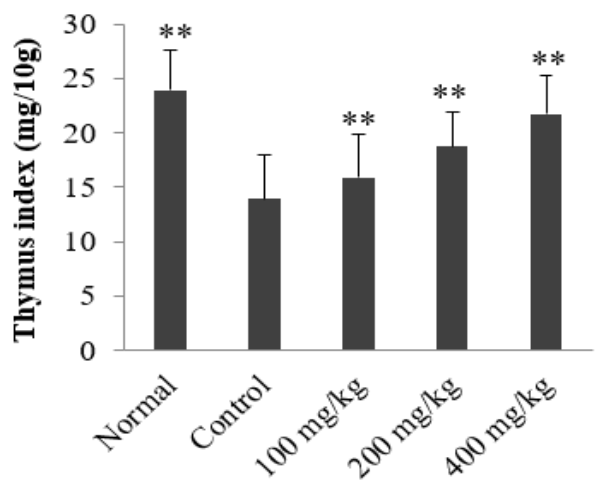

Figure 1: Thymus and spleen indices of CTX-treated mice; ${ }^{*} p<0.05,{ }^{* *} p<0.01$, compared with control

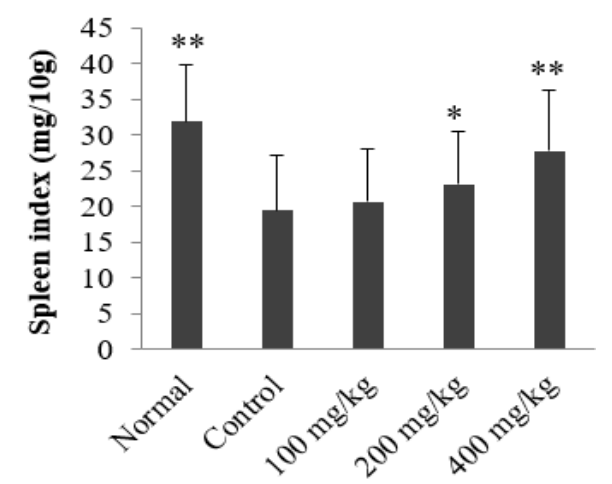

\section{MOP increased IL-6 and IL-3 in serum}

In this investigation, levels of IL-6 and IL-3 in serum were also studied. As can be seen from Figure 2, similar to the thymus and spleen indices, IL-6 and IL-3 were decreased by injection of CTX (80 $\mathrm{mg} / \mathrm{kg}, p<0.01)$. Interestingly, compared with the control mice, IL6 level in serum were increased by treatment with $\operatorname{MOP}(100,200$ and $400 \mathrm{mg} / \mathrm{kg}, p<0.01)$ in a dose-dependent manner. Besides, IL-3 in serum was also increased by MOP (100, 200 and $400 \mathrm{mg} / \mathrm{kg}$ ) compared to the control mice ( $p$ $<0.05, p<0.01, p<0.01$ ).

\section{DISCUSSION}

It is reported that plant-derived polysaccharides possess multiple pharmacological activities and relatively low toxicity, and in particular several polysaccharides exhibit notable immune stimulating effects and could be used to treat tumors and leukopenia [11,14]. This study investigated the optimum extraction of polysaccharide of Morinda officinalis (MOP), and also indicated that MOP stimulated synthesis

Trop J Pharm Res, September 2017; 16(9): 2158 

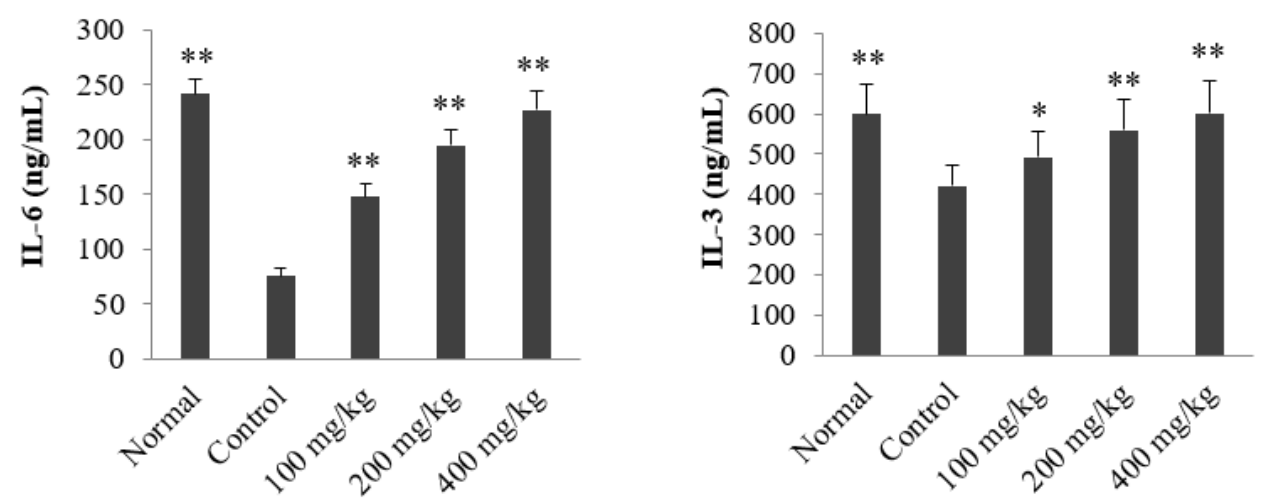

Figure 2: Serum IL-6 and IL-3 in CTX-treated mice; ${ }^{*} p<0.05,{ }^{* *} p<0.01$, compared with control

of leukocytes on leukopenia induced by CYT for first time.

Orthogonal design is one of the most popular experimented design methods to select representative parameters for replacing full factorial experiment with a less expensive, faster and partial factorial experiment $[15,16]$. Based on the range analysis, the factors' influence could be ordered, and ANOVA could estimate relative significance of each factor according to percentage contribution to the overall response [16]. In this study, based on the range analysis and ANOVA, the MOP extraction parameters were optimized: extraction temperature $\left(80^{\circ} \mathrm{C}\right)$, extraction time $(2 \mathrm{~h})$, extraction times (3), and ratio of water to raw material weight $(30 \mathrm{~mL} / \mathrm{g})$.

Cyclophosphamide (CTX) is a commonly used anticancer drug in the clinic and could result in several side-effects, especially leukopenia $[17,18]$. Therefore, CTX induced leukopenia in mice model is one of the most used animal model for evaluation of leukocyte inducing drugs [4]. In the present study, leukopenic BALB/c mice were successfully prepared with CTX injection. Immune organs, such as thymus and spleen, are crucial for the growth and development of leukocytes. The results indicated that MOP could increase thymus and spleen indices, suggesting that MOP might be beneficial for the growth and development of leukocytes. Previous investigations indicated that IL-3 and IL-6 could promote the proliferation and differentiation of leukocytes $[19,20]$. Interestingly, results of this study also revealed that MOP could increase the serum levels of IL-3 and IL-6, which is also beneficial for the proliferation and differentiation of leukocytes.

\section{CONCLUSION}

For optimum extraction of polysaccharide of $M$. officinalis (MOP), the extraction parameters are extraction temperature $\left(80^{\circ} \mathrm{C}\right)$, extraction time $(2$ h), extraction times (3), and ratio of water to raw material weight $(30 \mathrm{~mL} / \mathrm{g})$. Furthermore, the isolated polysaccharide also possesses notable leukocyte inducing-like effects and therefore is a potential adjunct therapeutic agent for the treatment of tumors/cancers.

\section{DECLARATIONS}

\section{Acknowledgement}

None.

\section{Conflict of Interest}

No conflict of interest associated with this work.

\section{Contribution of Authors}

The authors declare that this work was done by the authors named in this article and all liabilities pertaining to claims relating to the content of this article will be borne by them. Yaxin Zhao and Meng Wang contributed equally to this work.

\section{Open Access}

This is an Open Access article that uses a funding model which does not charge readers or their institutions for access and distributed under the terms of the Creative Commons Attribution License (http://creativecommons.org/licenses/by/ 4.0) and the Budapest Open Access Initiative (http://www.budapestopenaccessinitiative.org/rea d), which permit unrestricted use, distribution, and reproduction in any medium, provided the original work is properly credited.

\section{REFERENCES}

1. Siegel R, Ma J, Zou Z, Jemal A. Cancer statistics, 2014. CA Cancer J Clin 2014; 64: 9-29.

2. Hui MK, Wu WK, Shin $V Y$, so $W H$, cho $\mathrm{CH}$. Polysaccharides from the root of Angelica sinensis 
protect bone marrow and gastrointestinal tissues against the cytotoxicity of cyclophosphamide in mice. Int $\mathrm{J}$ Med Sci 2006; 3: 1-6.

3. Blumenthal RD, Albert R, Evelyn L, Goldenberg DM. Modulation of marrow proliferation and chemosensitivity by tumor-produced cytokines from syngeneic pancreatic tumor lines. Clin Cancer Res2002; 8: 1301 1309.

4. Yang DX, Ren HX, Chu Y, Li BA, Hu XM. Effect of cornel polysaccharides (CPS) on cyclophosphamide induced leucopenia in mice. Chin Arch Trad Chin Med 2009; 27. 1296-1297.

5. Gao F, Hu XF. Analysis of the therapeutic effect of sodium copper chlorophyll in tablet in treating 60 cases of leukopenia. Chin J Integr Med 2005; 11: 279-282.

6. Zhang $A H$, Sun $H$, Wang $P$, Han $Y$, Wang XJ. Future perspectives of personalized medicine in traditional Chinese medicine: A systems biology approach. Compl Ther Med 2012; 20: 93-99.

7. Li JWH, Vederas JC. Drug discovery and natural products: end of an era or an endless frontier? Sci2009; 325: 161.

8. Zhang Z, Zhang Q, Yang H, Liu W, Zhang N, Qin L, Xin $H$. Monotropein isolated from the roots of Morinda officinalis increases osteoblastic bone formation and prevents bone loss in ovariectomized mice. Fitoterapia 2016; 110: 166-172.

9. Chen Z, Fang DN, Ji MH. Effect of Morinda officinalis How decoction on immune function in mice. Bull Sci Technol 2003; 19: 244-246.

10. Zou ZJ, Xie YY, Gong MJ, Han B, Wang SM, Liang SW. Urine metabonomic study of intervention effects of Morinda officinalis how. on 'kidney-yang deficiency syndrome'. Yao Xue Xue Bao 2013; 48: 1733-1737.

11. "Principles of Laboratory Animal Care" (NIH publication no. 85-23, revised 1985). Available from: http://grants 1.nih.gov/grants/olaw/references/phspol.htm

12. Zhao C, Li M, Luo YF, Wu WK. Isolation and structural characterization of an immunostimulating polysaccha- ride from fuzi, Aconitum carmichaeli. Carbohyd Res 2006; 341: 485-491.

13. Xia YG, Kuang $H X$, Yang BY, Wang $Q H$, Liang J, Sun $Y$, Wang $\mathrm{YH}$. Optimum extraction of acidic polysaccharides from the stems of Ephedra sinica Stapf by Box-Behnken statistical design and its anti-complement activity. Carbohyd Polym 2011; 84: 282-291.

14. Tian XK, Lv HD, Zhao QH, Hao SJ, Geng XL. Effects of Yifukang oral liquid on chemotherapy-and radiotherapyinduced toxic and side effects of myelosuppression, leucopenia and gastrointestinal tract disturbances. Trop J Pharm Res 2015; 14: 2023-2030.

15. Zha $X Q$, Luo JP, Luo SZ, Jiang ST. Structure identification of a new immune stimulating polysaccharide from the stems of Dendrobium huoshanense. Carbohyd Polym 2007; 69: 86-93.

16. Tang JC, Gong GC, Su H, Wu FH, Herman C. Performance evaluation of a novel method of frost prevention and retardation for air source heat pumps using the orthogonal experiment design method. App Energ 2016; 169: 696-708.

17. Jiang JP, Luo $Z Y$, Chen $H$, Zhou $D$, Sha $D H$, Fang $M X$, Cen KF. Orthogonal design process optimization for particle charge distribution of mosquito coil smoke aerosol enhanced by pulsed corona discharge. Powd Technol 2015; 286: 507-515.

18. Peng W, Hu C, Shu Z, Han T, Qin L, Zheng C. Antitumor activity of tatariside $F$ isolated from roots of Fagopyrum tataricum (L.) Gaertn against H22 hepatocellular carcinoma via up-regulation of p53.Phytomed2015; 22: 730-736.

19. Gao LJ, Wang J, Huang X, Liu HX. Effects of putishengyin on leukoytopenia in mice. Chin $J$ Pract Med 2008; 35: 12-13.

20. Kasakura S. Cytokines and hematology. Int $J$ Hematol 2001; 74: 1-2.

21. Berger M, Fagioli F, Piacibello W. Role of different medium and growth factors on placental blood stem cell expansion: an in vitro and in vivo study. Bone Marrow Transpl 2002; 29: 443-448.s 